\title{
Budget Impact Analysis of Metformin Sustained Release for the Treatment of Type 2 Diabetes in The Netherlands
}

\author{
Judith J. Gout-Zwart ${ }^{1,2}$ (1) $\cdot$ Lisa A. de Jong ${ }^{3} \cdot$ Lisanne Saptenno ${ }^{3} \cdot$ Maarten J. Postma $^{3,4,5}$
}

Published online: 18 September 2019

(c) The Author(s) 2019

\begin{abstract}
Background Adverse drug reactions and medication nonadherence are well-known causes of sub-optimal disease control and worsened disease outcomes in patients who are treated for type 2 diabetes. Metformin sustained release (SR) might reduce these adverse events and improve medication adherence via a simplified treatment regimen for metformin immediate release (IR)-intolerant patients.

Objectives The aim of this study is to estimate the budget impact of metformin SR for the treatment of type 2 diabetes in the Netherlands, compared to the current standard of care (SoC) with metformin IR.

Methods A budget impact model was built to represent the course of the disease and treatment pathway of type 2 diabetes patients eligible for metformin SR from a healthcare payer's perspective. Patients were considered eligible if they used less than $2000 \mathrm{mg}$ metformin IR per day, but suffered from adverse events that might lead to therapy discontinuation, and if they were newly diagnosed with type 2 diabetes. The costs of type 2 diabetes treatment and related complications over a time horizon of 3 years were calculated. Univariate sensitivity analyses were conducted to show which parameters have the biggest influence on the budget impact.

Results The budget impact analysis showed cost-savings of $-€ 1,962,335$ over a period of 3 years through implementation of metformin SR as an alternative to SoC with metformin IR. Savings were mostly driven by the delay of other, more expensive type 2 diabetes treatments, such as insulin. In sensitivity analyses, medication adherence and persistence appeared to have the biggest influence on the budget impact.

Conclusion Metformin SR could potentially be a cost-saving alternative to metformin IR for the treatment of type 2 diabetes in the Netherlands, especially in patients experiencing adverse events with metformin IR. However, more research is needed to better predict the effect of using once-daily metformin, compared to multiple dosages, on medication adherence and persistence and to evaluate whether metformin SR really decreases the amount of adverse events.
\end{abstract}

\section{Key Points for Decision Makers}

Using metformin sustained release (SR) might be a costsaving alternative to the standard of care with metformin immediate release, due to the delay of other, more expensive treatments.

Adherence and persistence to metformin SR have a high impact on the results of the budget impact analysis.

Electronic supplementary material The online version of this article (https://doi.org/10.1007/s41669-019-00179-6) contains supplementary material, which is available to authorized users.

Judith J. Gout-Zwart

judith@ascacademics.com

Extended author information available on the last page of the article

\section{Introduction}

The population with type 2 diabetes mellitus is expanding rapidly due to ageing of the population and increased obesity. Estimations show an increase from 1.1 million in 2017 up to 1.3 million patients diagnosed with diabetes in 2025 in the Netherlands, out of which $91 \%$ will have type 2 diabetes [1,2]. In 2015, the cost of diabetes care was approximately $€ 1.6$ billion, which was $1.8 \%$ of total healthcare expenditures.

Diabetes is characterized by a high blood glucose, or so called hemoglobin A1c (HbA1c), level of $>7 \%$ $(>53 \mathrm{mmol} / \mathrm{mol}$ ). Lowering these levels is of great importance for controlling the disease. Type 2 diabetes is associated with severe macro- and microvascular complications, such as cardiovascular disease, foot amputations, renal disease and visual impairment, especially in patients with 
poor metabolic control. Sufficient management of diabetes and, therefore, properly controlled $\mathrm{HbA} 1 \mathrm{c}$ levels are essential for reducing the risk of these complications [3].

Good metabolic control by oral type 2 diabetes treatment could possibly delay other, more invasive treatments, like insulin. Treatment with metformin immediate release (IR) has proven to be effective in clinical trials; however, adverse events (AEs) are a common problem. A Dutch study showed that $34.5 \%$ of the patients on metformin IR experienced AEs, and 11.4-16.1\% discontinued their treatment within the first year after initiation $[4,5]$. Medication nonadherence, partially due to (gastrointestinal) AEs and difficult treatment regimens, is a well-known problem in type 2 diabetes patients [6]. A switch from metformin IR to metformin sustained release (SR) might offer an improvement in experienced gastrointestinal AEs when metformin IR is not tolerated [7-9]. Reducing the amount of AEs has the potential to improve medicine compliance and adherence, which subsequently might reduce the need for other, more expensive antidiabetic drugs and potentially promote better long-term health outcomes [10-12]. Also, once-daily dosing may simplify the treatment regimen for type 2 diabetes patients and contribute to better treatment adherence. Therefore, metformin SR might improve glycemic control, ultimately reducing the risk of severe diabetes complications and postponing the use of other, more expensive antidiabetic drugs.

Various studies have shown therapeutic equivalency or even benefit of metformin SR when compared to metformin IR, with comparable glycemic control and sometimes a more favorable AE profile [7, 10,11,13-15]. The economic value, however, has not yet been determined. Therefore, the aim of this study was to perform a budget impact analysis (BIA) of the implementation of metformin SR compared to standard of care (SoC) with metformin IR for the treatment of type 2 diabetes in the Netherlands.

\section{Methods}

\subsection{Model Design}

Following the International Society for Pharmacoeconomics and Outcomes Research (ISPOR) guidelines "Principles of Good Practice for Budget Impact Analysis," a BIA was conducted using a model built in Microsoft Excel 2016 [16, 17]. This model evaluated the impact of introducing metformin $\mathrm{SR}$, as an alternative to metformin IR, for the treatment of type 2 diabetes against a background of other antidiabetics (Fig. 1). Several studies showed comparable efficacy and safety for metformin SR when compared to metformin IR. Most of these studies, however, are considered "switchstudies," meaning patients included in the metformin SR population have already experienced AEs from metformin IR. This leads to bias, which is why AEs were not included in this model [7, 10, 11, 13-15].

Figures 2 and 3 show the treatment pathway of patients who are treated following $\mathrm{SoC}$, but are eligible for metformin SR, over a period of 3 years. Patients in Fig. 2 switched to metformin SR, and patients in Fig. 3 keep using metformin IR. Within these years, they could either keep using metformin or switch to other medications. Besides these metformin IR-intolerant patients, 67,249 newly diagnosed type 2 diabetes patients who initially started metformin SR treatment in year 1 were considered as well (Figs. 4, 5) [18, 19]. Guidelines from the Dutch College of General Practitioners (Nederlands Huisartsen Genootschap [NHG]) were used to outline the treatment pathway of type 2 diabetes patients [20]. Persistency was modeled based on a study that assessed the transition rates of patients with type 2 diabetes between different drugs (classes) (Figs. 2, 3, 4, 5) [21].

Following the ISPOR guidelines, we simulated the treatment pathway of each individual patient over a 3-year time horizon, based on annual persistence rates per type
Fig. 1 Flow through of the budget impact model. $H b A 1 c$ hemoglobin A1c, IR immediate release, $O L G D$ other glucoselowering drugs, $S R$ sustained release
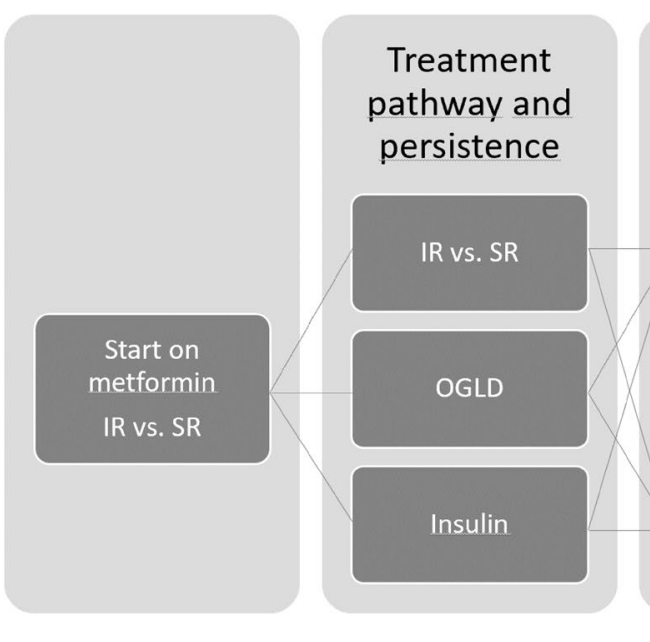

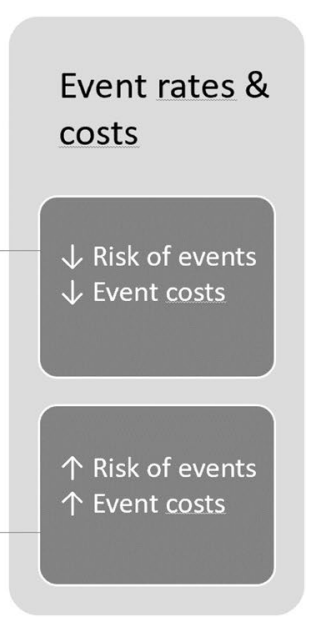


2 diabetes drug category. Drug categories taken into consideration were (1) metformin, (2) other glucose-lowering drugs (OGLDs: sulphonylurea derivatives, thiazolidinediones, alpha-glucosidase inhibitors, glinides, dipeptidyl peptidase-4 [DPP-4] inhibitors, glucagon-like peptide-1 [GLP-1] agonists, sodium-glucose co-transporter-2 [SGLT-2] inhibitors) and (3) insulin. Following the distribution of patients through the treatment pathway in the model, the possibility of medication (non)adherence was assessed and corresponding probabilities of $\mathrm{HbA} 1 \mathrm{c}$ goal achievement were included [22-24]. Studies in patients using metformin SR showed adherence rates ranging between 80 and $97.2 \%$ [14, 25-27]. In this model, we assumed adherence to metformin SR in year 1 as $90 \%$, mostly related to the simplified dosing regimen, and adherence to metformin IR was approximately $72 \%$. Although the effects of nonadherence on achieved $\mathrm{HbA} 1 \mathrm{c}$ have been studied for many antidiabetic drugs, the relation is not quantified for all glucose-lowering drugs. Using pooled data on HbA1c target achievement, the drugs for which quantification was missing were graded under one common denominator: OLGD [24]. Based on the Dutch and international guidelines for type 2 diabetes treatment, the HbA1c target value was set to $\leq 7 \%(\leq 53 \mathrm{mmol} / \mathrm{mol})$ [20,
Fig. 2 Treatment pathway of SR eligible type 2 diabetes patients currently on SoC who are switched to SR [21]. INS insulin, $O G L D$ other glucoselowering drug, $S o C$ standard of care, $S R$ sustained release

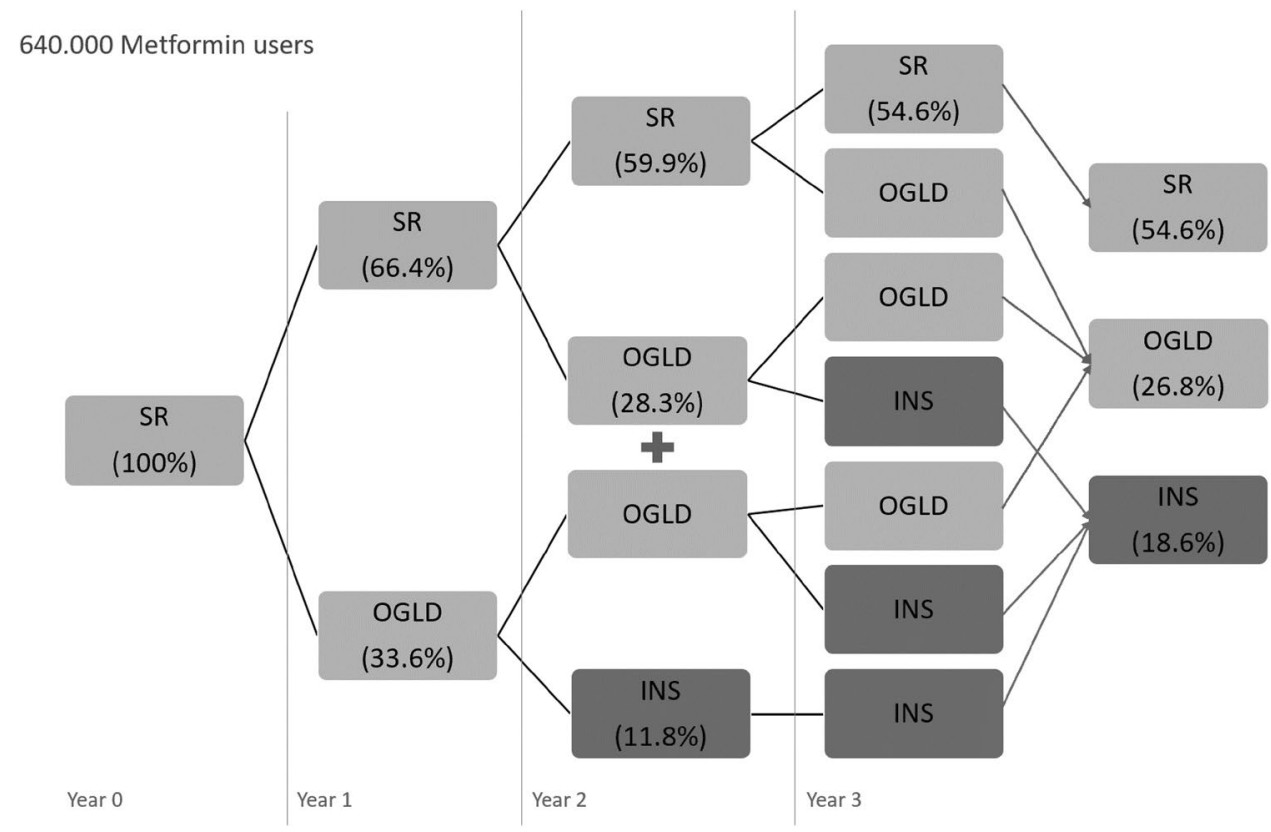

Fig. 3 Treatment pathway of SR eligible type 2 diabetes patients currently on metformin IR who stay on IR [21]. INS insulin, $I R$ immediate release, $O G L D$ other glucose-lowering drug, $S R$ sustained release

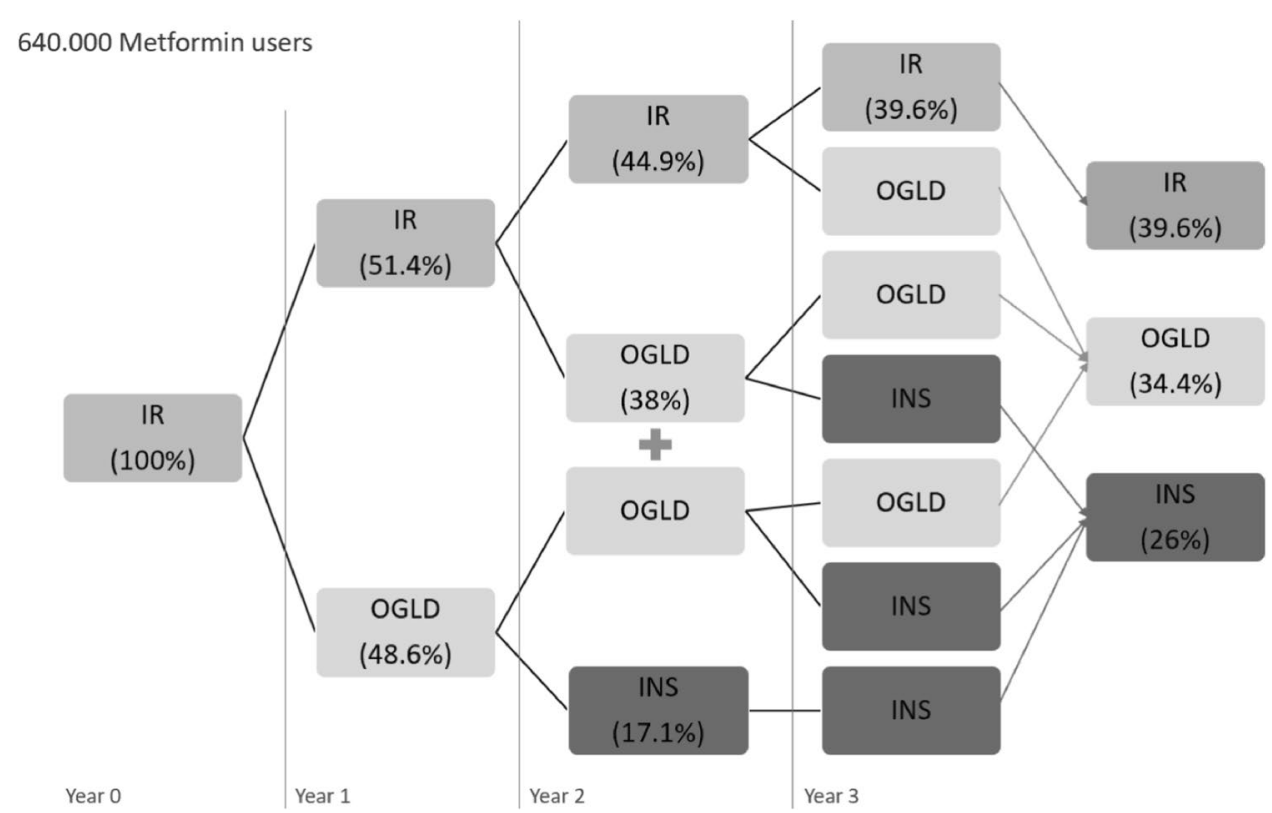


Fig. 4 Treatment pathway of newly diagnosed type 2 diabetes patients eligible for SR who start on SR [21]. INS insulin, $O G L D$ oral glucose-lowering drug, $S R$ sustained release
Fig. 5 Treatment pathway of newly diagnosed type 2 diabetes patients eligible for SR who start on IR [21]. INS insulin, IR immediate release, $O G L D$ oral glucose-lowering drug, $S R$ sustained release
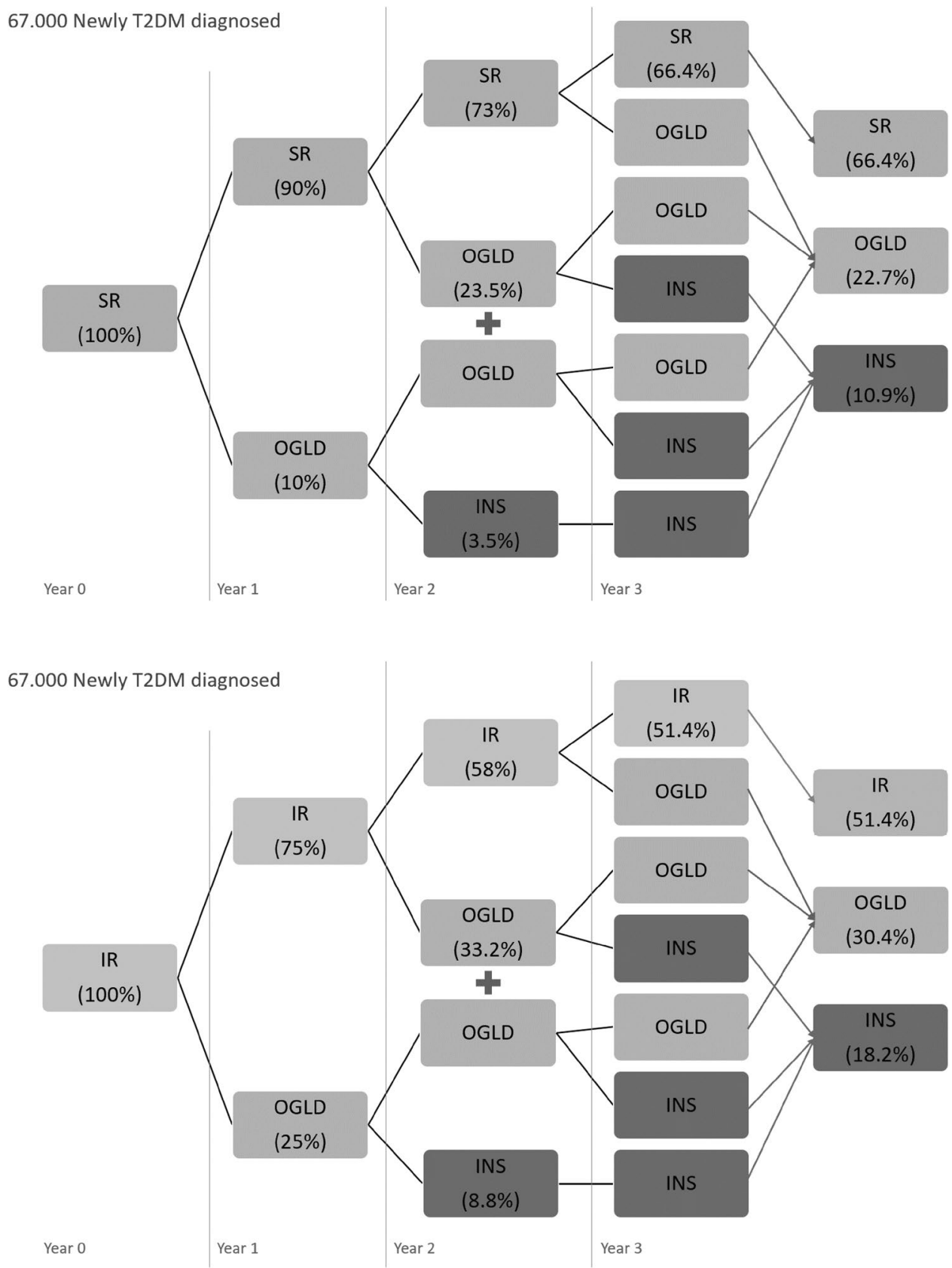

$28,29]$. Consequently, categories representing "goal" or "no goal" were set to $\mathrm{HbA} 1 \mathrm{c} \leq 7 \%(\leq 53 \mathrm{mmol} / \mathrm{mol})$ or $\mathrm{HbA} 1 \mathrm{c}>7 \%$ (> $53 \mathrm{mmol} / \mathrm{mol}$ ), respectively. Probabilities of developing type 2 diabetes related macro- and microvascular complications were linked to the obtained $\mathrm{HbA} 1 \mathrm{c}$ levels per treatment (Table 1) [30].

The analysis was conducted from a healthcare payers' perspective. The influence of different parameters on the budget impact was assessed by univariate sensitivity analyses over a time horizon of 3 years, which was chosen to match the payers' budgeting process [17].

\subsection{Study Population}

The baseline study population included in the model was obtained from Dutch metformin user numbers, as reported in the Dutch drug information system of the National Health Care Institute (GIPdatabank), and was estimated at 640,000 [31]. Patients on metformin IR dosages higher than $2000 \mathrm{mg}$ daily were excluded, since switching from metformin IR to SR is not recommended when the daily dosage of metformin IR is above $2000 \mathrm{mg}$. Also the maximum recommended dosage for patients starting metformin SR from the start of type 2 diabetes treatment is $2000 \mathrm{mg}$ 
Table 1 Event rates per 1000 person years for sufficient and non-sufficient $\mathrm{HbA1c}$ management [30]

\begin{tabular}{lll}
\hline Event & $\begin{array}{l}\text { Goal } \\
(\text { HbA1c } \leq 7 \%)\end{array}$ & $\begin{array}{l}\text { No goal } \\
(\mathrm{HbA1c}>7 \%)\end{array}$ \\
\hline All-cause mortality & 0.0206 & 0.0324 \\
(Non)fatal MI & 0.0187 & 0.0317 \\
(Non)fatal stroke & 0.0056 & 0.0081 \\
Amputation/death from peripheral & 0.0012 & 0.0049 \\
$\quad$ vascular disease & & \\
(Non)fatal microvascular disease & 0.0079 & 0.0238 \\
Heart failure & 0.0029 & 0.0053 \\
Cataract extraction & 0.0043 & 0.0065 \\
\hline
\end{tabular}

$H b A 1 c$ hemoglobin A1c, $M I$ myocardial infarction

[32, 33]. As metformin SR is an alternative to metformin IR, we identified which patients would be able to switch from SoC to metformin SR and who would continue on metformin IR. Factors considered in this respect were (1) the discontinuation of metformin IR amongst newly diagnosed patients $(16.1 \%),(2)$ the potential market share of metformin SR as calculated from medicine issue registries from the United Kingdom (22.53\%), and (3) the percentage of patients currently on metformin IR who could be actively switched to metformin SR (0.1\%) [5]. As this BIA covers multiple years, type 2 diabetes patient population growth was taken into account. This was calculated by the number of newly diagnosed patients minus the number of deaths, where the number of newly diagnosed patients was estimated to be 67,000 by the Dutch healthcare research institute NIVEL (2016) [19, 30, 34]. Transition probabilities are displayed in the electronic supplementary material (ESM).

\subsection{Data Collection}

To represent the baseline use of metformin IR as accurately as possible, data were collected from three pharmacies representative of the Netherlands by pharmatech company Medstone [35]. These data were used to determine the average cost of metformin use in the Netherlands. The data were collected from one pharmacy situated in a city, one in a more rural area and one in a small village between August 1, 2017 and July 31, 2018 and using Anatomical Therapeutic Chemical (ATC) classification system code A10BA02. Further data handling is described in supplementary Fig. 7 (see the "Data handling metformin use" section in the ESM). Based on the summary of product characteristics (SmPC) recommendations, patients who used more than $2000 \mathrm{mg}$ metformin IR were excluded from the model, leaving information on 847 prescriptions from unique patients. The obtained data
Table 2 Metformin IR use and breakdown of the daily dosage

\begin{tabular}{lrllll}
\hline $\begin{array}{l}\text { Daily } \\
\text { dosage } \\
(\mathrm{mg})\end{array}$ & \begin{tabular}{l} 
Breakdown \\
\cline { 2 - 5 }$(\mathrm{mg})$
\end{tabular} & $\begin{array}{l}\text { Number } \\
\text { of tablets }\end{array}$ & $\begin{array}{l}\text { Tablet } \\
(\mathrm{mg})\end{array}$ & $\begin{array}{l}\text { Number } \\
\text { of tablets }\end{array}$ & $\begin{array}{l}\text { Number of } \\
\text { prescrip- } \\
\text { tions }(\%)\end{array}$ \\
\hline 500 & 500 & 1 & & & $197(23.26)$ \\
850 & 850 & 1 & & $5(0.59)$ \\
1000 & 1000 & 1 & & & $8(0.94)$ \\
& 500 & 2 & & & $288(34.00)$ \\
1350 & 850 & 1 & 500 & 1 & $1(0.12)$ \\
1500 & 500 & 3 & & & $103(12.16)$ \\
& 1000 & 1 & 500 & 1 & $3(0.35)$ \\
1700 & 850 & 2 & & & $26(3.07)$ \\
1850 & 850 & 1 & 500 & 2 & $1(0.12)$ \\
2000 & 500 & 4 & & & $120(14.17)$ \\
& 1000 & 1 & 500 & 2 & $4(0.47)$ \\
& 1000 & 2 & & & $91(10.47)$ \\
Total & & & & & $847(100)$ \\
\hline
\end{tabular}

$I R$ immediate release

included information on the total daily dosage, tablet breakdown and the number of prescriptions (Table 2).

Research has shown the daily dosages of both metformin formulations are compatible [36]. To convert the use of metformin IR to metformin SR, we assumed that the distribution of patients using certain tablet regimens was similar between both formulations. However, because metformin IR is available as $500 \mathrm{mg}, 850 \mathrm{mg}$ and $1000 \mathrm{mg}$ and metformin SR as $500 \mathrm{mg}, 750 \mathrm{mg}$ and $1000 \mathrm{mg}$, some assumptions had to be made regarding the daily dosage of metformin SR (Table 3).

\subsection{Costs}

Costs are shown in Table 4 and the ESM ("Drug cost overview" section). Annual drug costs per patient per daily dosage (or insulin unit) were calculated using the prescription standard for type 2 diabetes from the National Health Care Institute (Zorginstituut Nederland [ZIN]) [37, 38]. The annual costs of metformin SR are calculated based on the assumption of a once-daily treatment regimen. The BIA only includes costs as paid by the healthcare payer, therefore excluding the patient's own contribution to the total product price. Costs of insulin care and non-insulin care were based on information as provided by the Dutch Diabetes Foundation (Diabetes Vereniging Nederland) and was combined with treatment costs from health insurer declarations [39, 40]. Insulin care consisted of medication, testing strips, blood glucose measuring device, blood extraction equipment, insulin pens and syringes, remaining diabetes tools, an insulin pump and regular checkups/coaching at the ophthalmologist or with a diabetes nurse. Non-insulin care costs consisted of medication, regular checkups and 
Table 3 Metformin IR versus metformin SR treatment regimens

\begin{tabular}{lc}
\hline Daily dosage metformin IR (mg) & $\begin{array}{l}\text { Daily dosage } \\
\text { metformin SR } \\
(\mathrm{mg})\end{array}$ \\
\hline 500 & 500 \\
850 & 750 \\
1000 & 1000 \\
1350 & 1250 \\
1500 & 1500 \\
1700 & 1500 \\
1850 & 1750 \\
2000 & 2000 \\
\hline
\end{tabular}

$I R$ immediate release, $S R$ sustained release

Table 4 Costs included in the budget impact analysis, 2018 price levels

\begin{tabular}{|c|c|c|}
\hline & $\begin{array}{l}\text { Cost per patient } \\
\text { per year }\end{array}$ & References \\
\hline \multicolumn{3}{|l|}{ Treatment costs } \\
\hline Metformin SR $500 \mathrm{mg}$ & $€ 21.41$ & {$[37]$} \\
\hline Metformin SR $750 \mathrm{mg}$ & $€ 32.00$ & {$[37]$} \\
\hline Metformin SR $1000 \mathrm{mg}$ & $€ 42.71$ & {$[37]$} \\
\hline Metformin IR $500 \mathrm{mg}$ & $€ 5.23$ & {$[37]$} \\
\hline Metformin IR $850 \mathrm{mg}$ & $€ 8.88$ & {$[37]$} \\
\hline Metformin IR $1000 \mathrm{mg}$ & $€ 10.10$ & {$[37]$} \\
\hline SGLT-2 inhibitor & $€ 579.19$ & {$[37]$} \\
\hline Sulphonylurea derivatives & $€ 25.42$ & {$[37]$} \\
\hline Thiazolidinediones & $€ 13.63$ & {$[37]$} \\
\hline Alpha-glucosidase inhibitor & $€ 230.68$ & {$[37]$} \\
\hline Glinide & $€ 131.04$ & {$[37]$} \\
\hline DPP-4 inhibitor & $€ 493.32$ & {$[37]$} \\
\hline GLP-1 agonist & $€ 1210.03$ & {$[37]$} \\
\hline Insulin (per unit, IU) & $€ 0.03$ & [37] \\
\hline Insulin care & $€ 456.17$ & {$[37]$} \\
\hline Non-insulin cost usual care & $€ 645.00$ & {$[37]$} \\
\hline \multicolumn{3}{|l|}{ Event costs } \\
\hline (Non)fatal MI & $€ 5309$ & {$[42]$} \\
\hline (Non)fatal stroke & $€ 14,280$ & {$[42]$} \\
\hline $\begin{array}{l}\text { Amputation/death from peripheral } \\
\text { vascular disease }\end{array}$ & $€ 61,084$ & {$[42]$} \\
\hline (Non)fatal microvascular disease & $€ 94,557$ & {$[42]$} \\
\hline Heart failure & $€ 2966$ & {$[42]$} \\
\hline Cataract extraction & $€ 3054$ & {$[42]$} \\
\hline
\end{tabular}

$D P P-4$ dipeptidyl peptidase-4, GLP-1 glucagon-like peptide-1, IR immediate release, $M I$ myocardial infarction, $S G L T$-2 sodium-glucose co-transporter-2, $S R$ sustained release

coaching by a professional $[39,40]$. All costs were inflated to the year 2018, using Dutch inflation rates [41]. For the BIA, discounting was not applied, as it was our goal to show financial streams at each selected budget period and not the net present value at the moment of decision-making [17].

\section{Results}

\subsection{Budget Impact Analysis}

Over 3 years, the total economic burden of type 2 diabetes controlled with metformin IR was $€ 45,723,744$. This, compared to the burden of using metformin SR for treatment of type 2 diabetes over 3 years, which was $€ 43,761,409$, leads to cost savings of $€ 1,962,335$. No acquisition cost savings were seen in year 1, but during the next 2 years, cost savings substantially increased. Also type 2 diabetes event cost savings increased over the years; however, not as strongly (Table 5).

\subsection{Sensitivity Analysis}

In the univariate sensitivity analysis, parameters were varied over a range from $75 \%$ to $125 \%$. Out of the 53 variables included in the analysis, 15 parameters with the biggest influence on the outcome are shown in Fig. 6. The tornado diagram shows that not achieving HbA1c targets resulting from medication adherence or persistence was most influential. Low adherence or persistence might make the use of metformin SR more costly than metformin IR.

\section{Discussion}

Several studies have assessed the therapeutic differences between metformin IR and metformin SR in an attempt to demonstrate metformin SR's added value [7, 10, 11]. However, the economic impact of using metformin SR in routine clinical practice for the treatment of type 2 diabetes in the Netherlands has not yet been quantified.

The results of this BIA show that metformin SR could be a cost-saving alternative to metformin IR in the treatment of type 2 diabetes. The resulting differences in costs between the two formulations are mostly caused by differences in acquisition costs. This can be explained by a wide variety in metformin treatment regimens amongst the type 2 diabetes patient population and the corresponding treatment costs. Drug costs included in the model are chosen conservatively, always choosing the cheapest treatment option when more than one was possible. Furthermore, the metformin SR prices included in the model are the upper reimbursement limits, as set by the government. To properly reflect the payers' perspective, it is necessary to include the drug prices as paid by the healthcare payer. 
Table 5 Results budget impact analysis

\begin{tabular}{|c|c|c|c|c|c|c|}
\hline & \multicolumn{3}{|c|}{ Metformin IR } & \multicolumn{3}{|c|}{ Metformin SR } \\
\hline & Year 1 & Year 2 & Year 3 & Year 1 & Year 2 & Year 3 \\
\hline Acquisition cost & $€ 2,061,721$ & $€ 4,096,323$ & $€ 6,309,202$ & $€ 2,128,603$ & $€ 3,997,456$ & $€ 6,007,782$ \\
\hline MI & $€ 415,665$ & $€ 743,836$ & $€ 1,066,591$ & $€ 404,490$ & $€ 723,412$ & $€ 1,037,354$ \\
\hline Stroke & $€ 300,786$ & $€ 537,283$ & $€ 769,386$ & $€ 295,099$ & $€ 526,889$ & $€ 754,507$ \\
\hline Amputation & $€ 602,622$ & $€ 1,086,865$ & $€ 1,567,360$ & $€ 565,633$ & $€ 1,019,258$ & $€ 1,470,580$ \\
\hline Microvascular disease & $€ 4,766,415$ & $€ 8,576,388$ & $€ 12,346,956$ & $€ 4,523,268$ & $€ 8,131,975$ & $€ 11,710,778$ \\
\hline Heart failure & $€ 38,104$ & $€ 68,239$ & $€ 97,903$ & $€ 36,952$ & $€ 66,133$ & $€ 94,889$ \\
\hline Cataract extraction & $€ 50,890$ & $€ 90,941$ & $€ 130,268$ & $€ 49,834$ & $€ 89,011$ & $€ 127,505$ \\
\hline Type 2 diabetes event cost & $€ 6,174,482$ & $€ 11,103,553$ & $€ 15,978,464$ & $€ 5,875,277$ & $€ 10,556,678$ & $€ 15,195,613$ \\
\hline Total cost & $€ 8,236,203$ & $€ 15,199,876$ & $€ 22,287,666$ & $€ 8, \mathbf{0 0 3}, \mathbf{8 8 0}$ & $€ 14,554,134$ & $€ 21,203,395$ \\
\hline Budget impact & & & & $-€ 232,323$ & $-€ 645,741$ & $-€ 1,804,271$ \\
\hline Total budget impact & & & & & & $-€ 1,962,335$ \\
\hline
\end{tabular}

$I R$ immediate release, $M I$ myocardial infarction, $S R$ sustained release

\section{Tornado diagram}

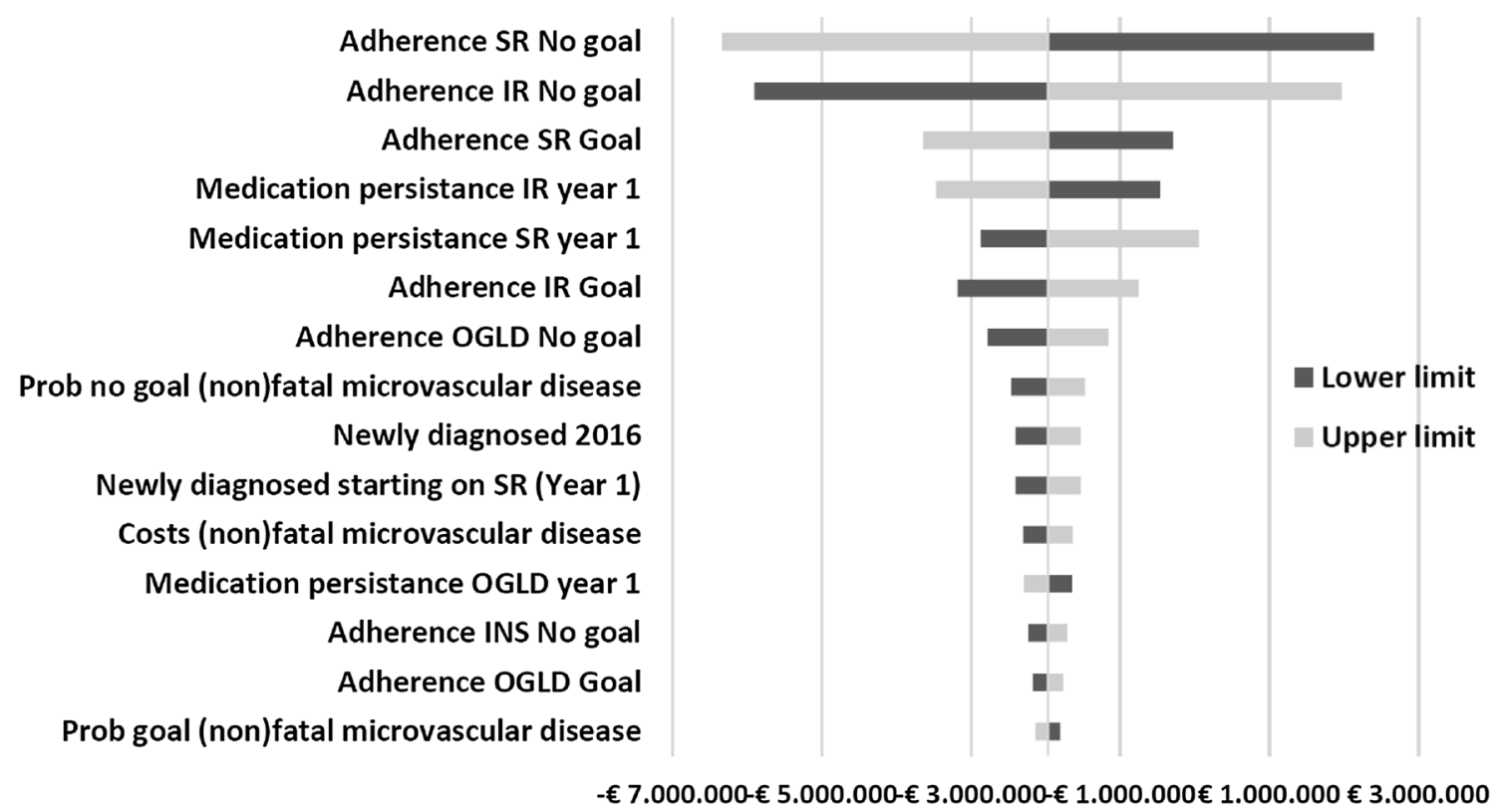

Fig. 6 Univariate sensitivity analysis. $I N S$ insulin, $I R$ immediate release, $O G L D$ other glucose-lowering drug, $S R$ sustained release

As do all economic analyses, this BIA has its limitations. In order to quantify the added economic value of metformin SR over metformin IR, several assumptions had to be made. Since there was a lack of data on the long-term patient treatment pathways, we simulated the flow of the estimated eligible patient population over all possible drug treatments as prescribed following the Dutch treatment guidelines for type 2 diabetes, while taking into account the treatment's market share [20, 43]. Future research, where type 2 diabetes patients are followed over a longer period of time, could provide viable data on treatment pathway utilization and the effects of metformin SR on changes in medication adherence and persistence. These data could validate assumptions, decrease uncertainty and increase the models predictive strength. Another drawback of the 3-year time horizon is that diabetes-related complications often occur within 5-10 years or even longer. Because a longer time horizon will require a considerable amount of assumptions and will therefore increase uncertainty, a long time horizon is not recommended [16, 17].

To calculate the cost of metformin SR use, we assumed a treatment regimen of one dose per day. This is also 
recommended by the manufacturer; however, if glycemic control is not satisfying, patients can switch to a dose regimen of metformin SR twice daily [32]. We expect this to be the case for a small amount of patients, and since it might only slightly change the price of the daily dosage, it will have a small effect on the outcome as well.

Although several studies have shown therapeutic equivalency between metformin SR and IR, there is also some evidence that shows metformin SR to be better tolerated, especially when it comes to gastrointestinal side effects [8, 44]. The savings that can be generated by implementing metformin SR could potentially be higher than are presented in this model.

The cut-off value for $\mathrm{HbA} 1 \mathrm{c}$ is set to $7 \%(53 \mathrm{mmol} / \mathrm{mol}$ ) to divide the patient population into two groups: proper glycemic control with lowered type 2 diabetes event risks and improper glycemic control with an increased risk of type 2 diabetes events. However, it should be mentioned that this cut-off is not applicable to all patient populations, as it cannot always be a realistic target. Doctors can deviate from this value based on a patients age, disease duration and life expectancy [20]. Because we calculated the event rates using patients with different $\mathrm{HbA} 1 \mathrm{c}$ targets, we predict the effect on the outcome to be negligible. Also, the predictive value of $\mathrm{HbA} 1 \mathrm{c}$ for reduction of mortality and complications is still up for debate, as it has not been inconclusively proven that a reduction of $\mathrm{HbAlc}$ results in a reduction of mortality or severe macro- and microvascular complications $[45,46]$.

As diabetes treatments are often added upon one another, it might be that the BIA underestimates the potential cost savings that could be achieved by the delay of other type 2 diabetes drugs. Not one drug, but multiple at the same time will be postponed. The accumulation of treatments, however, does not always result in improved disease outcomes. Therefore the need for suitable treatments from the start of the disease are needed as diabetes is a progressive disease which ultimately leads to deteriorating health [47].

\section{Conclusion}

Our budget impact model shows potential cost savings for metformin SR when compared to SoC with metformin IR for the treatment of type 2 diabetes in the Netherlands. However, to strengthen the model and its outcomes, more research on the therapeutic effects and patient-related outcomes of metformin SR is needed.

Author Contributions Lisa de Jong and Lisanne Saptenno designed the model. Judith Gout-Zwart validated the model and wrote the manuscript. Maarten Postma reviewed the manuscript. Judith Gout-Zwart and Lisa de Jong take responsibility for the content of the article.
Data Availability Statement All data generated or analyzed during this study are included in this published article and its supplementary information files.

\section{Compliance with Ethical Standards}

Funding This study was funded by Goodlife Pharma.

Conflict of interest Judith Gout-Zwart, Lisa de Jong and Lisanne Saptenno do not have any conflicts of interest to declare. Maarten Postma has received grants from various pharmaceutical companies, but none related to the work described here.

Open Access This article is distributed under the terms of the Creative Commons Attribution-NonCommercial 4.0 International License (http://creativecommons.org/licenses/by-nc/4.0/), which permits any noncommercial use, distribution, and reproduction in any medium, provided you give appropriate credit to the original author(s) and the source, provide a link to the Creative Commons license, and indicate if changes were made.

\section{References}

1. van Baan CA, Baal PHM, Jacobs-van der Bruggen MAM, Verkley $\mathrm{H}$, Poos MJJC, Hoogenveen RT, et al. Diabetes mellitus in the Netherlands: estimate of the current disease burden and prognosis for 2025. Ned Tijdschr Geneeskd. 2009;153:A580.

2. Volksgezondheidenzorg.info. Diabetes mellitus [Internet]. 2017. https://www.volksgezondheidenzorg.info/onderwerp/diabetesmellitus/cijfers-context/huidige-situatie.

3. Nathan DM, DCCT/EDIC Research Group. The Diabetes Control and Complications Trial/Epidemiology of Diabetes Interventions and Complications Study at 30 years: overview. Diabetes Care. 2014;37(1):9-16. http://www.ncbi.nlm.nih.gov/pubmed/24356 592. Accessed 21 Sep 2018.

4. De Jong L, Härmark L, Van Puijenbroek E. Time course, outcome and management of adverse drug reactions associated with metformin from patient's perspective: a prospective, observational cohort study in the Netherlands. Eur J Clin Pharmacol. 2016;72(5):615-22.

5. Plat A, Penning-van Beest F, Kessabi S, Groot M, Herings R. Change of initial oral antidiabetic therapy in type 2 diabetic patients. Pharm World Sci. 2009;31(6):622-6.

6. Sabaté E. Adherence to long-term therapies: evidence for action. World Heal Organ Publ. 2003.

7. Fujioka K, Pans M, Joyal S. Glycemic control in patients with type 2 diabetes mellitus switched from twice-daily immediate-release metformin to a one-daily extended-release formulation. Clin Ther. 2003;25(2):515-29.

8. Davidson J, Howlett H. New prolonged-release metformin improves gastrointestinal tolerability. Br J Diabetes Vasc Dis. 2004;4(4):273-7. https://doi.org/10.1177/147465140400400 41101.

9. Kim C-H, Han K-A, Oh H-J, Tan KE-K, Sothiratnam R, Tjokroprawiro A, et al. Safety, tolerability, and efficacy of metformin extended-release oral antidiabetic therapy in patients with type 2 diabetes: an observational trial in Asia. J Diabetes. 2012;4(4):395406. http://doi.wiley.com/10.1111/j.1753-0407.2012.00220.x. Accessed 1 Oct 2018.

10. Feher M, Al-Mrayat M, Brake J, Leong KS. Tolerability of prolonged-release metformin (Glucophage ${ }^{\circledR} \mathrm{SR}$ ) in individuals 
intolerant to standard metformin - results from four UK centres. Br J Diabetes Vasc Dis. 2007;7(5):225-8.

11. Jabbour S, Ziring B. Advantages of extended-release metformin in patients with type 2 diabetes mellitus. Postgrad Med. 2015;123(1):14-23.

12. Balkrishnan R, Rajagopalan R, Camacho FT, Huston SA, Murray $\mathrm{FT}$, Anderson RT. Predictors of medication adherence and associated health care costs in an older population with type 2 diabetes mellitus: a longitudinal cohort study. Clin Ther. 2003;25(11):2958-71. http://www.ncbi.nlm.nih.gov/pubme d/14693318. Accessed 21 Sep 2018.

13. Gao H, Xiao W, Wang C, Zhang J, Yang Y, Yang J, et al. The metabolic effects of once daily extended-release metformin in patients with type 2 diabetes: a multicentre study. Int J Clin Pract. 2008;62(5):695-700. https://doi.org/10.111 $1 / \mathrm{j} .1742-1241.2008 .01733 . x$.

14. Schwartz S, Fonseca V, Berner B, Cramer M, Chiang Y-K, Lewin A. Efficacy, tolerability, and safety of a novel once-daily extendedrelease metformin in patients with type 2 diabetes. Diabetes Care. 2006;29(4):759-64. http://www.ncbi.nlm.nih.gov/pubmed/16567 811. Accessed 20 Mar 2018.

15. Aggarwal N, Singla A, Mathieu C, Montanya E, Pfeiffer AFH, Johnsson E, et al. Metformin extended-release versus immediaterelease: an international, randomized, double-blind, head-to-head trial in pharmacotherapy-naïve patients with type 2 diabetes. Diabetes Obes Metab. 2018;20(2):463-7.

16. Mauskopf JA, Sullivan SD, Annemans L, Caro J, Daniel Mullins C, Nuijten M, et al. Principles of good practice for budget impact analysis: report of the ISPOR Task Force on Good Research Practices-Budget Impact Analysis. 2007;1098. https://www.value inhealthjournal.com/article/S1098-3015(10)60471-8/pdf?_retur nURL=https://linkinghub.elsevier.com/retrieve/pii/S109830151 0604718-showall:Dtrue. Accessed 6 Sep 2018.

17. Sullivan SD, Mauskopf JA, Augustovski F, Jaime Caro J, Lee KM, Minchin M, et al. Budget impact analysis-principles of good practice: Report of the ISPOR 2012 budget impact analysis good practice II task force. Value Heal. 2014.

18. Poortvliet MC, Schrijvers CTM, Baan CA. Diabetes in The Netherlands. RIVM Rapp. 2007;260322001:62.

19. volksgezondheidenzorg.info. Diabetes Mellitus [Internet]. https ://www.volksgezondheidenzorg.info/onderwerp/diabetes-melli tus/kosten/kosten\#node-kosten-van-zorg-voor-diabetes-mellitus. Accessed 23 Feb 2019.

20. NHG, Ruggen G, De Grauw W, Nijpels G, Houweling S, Laar F, et al. NHG-standard diabetes mellitus type 2. Derde Herziening. Huisarts Wet. 2013;56(10):512-25.

21. McGovern A, Hinton W, Calderara S, Munro N, Whyte M, de Lusignan S. A class comparison of medication persistence in people with type 2 diabetes: a retrospective observational study. Diabetes Ther. 2018;9(1):229-42.

22. Andersson C, Van Gaal L, Caterson ID, Weeke P, James WPT, Coutinho $\mathrm{W}$, et al. $\mathrm{HbA}(1 \mathrm{c})$ as a screening tool for detection of type 2 diabetes: a systematic review. Diabetes Care. 2011;13(3):333-43.

23. Dalal MR, Grabner M, Bonine N, Stephenson JJ, DiGenio A, Bieszk N. Are patients on basal insulin attaining glycemic targets? Characteristics and goal achievement of patients with type 2 diabetes mellitus treated with basal insulin and physician-perceived barriers to achieving glycemic targets. Diabetes Res Clin Pract. 2016;121:17-26.

24. Penning-van Beest FJA, van der Bij S, Erkens JA, Kessabi S, Groot M, Herings RMC. Effect of non-persistent use of oral glucose-lowering drugs on $\mathrm{HbA}_{1 \mathrm{c}}$ goal attainment. Curr Med Res Opin. 2008;24(9):2523-9.

25. Strojek K, Kurzeja A, Gottwald-Hostalek U. Patient adherence to and tolerability of treatment with metformin extended-release formulation in patients with type 2 diabetes. GLUCOMP study.
Clin Diabetol. 2016;5(1):15-21. https://journals.viamedica.pl/ diabetologia_kliniczna/article/view/47014. Accessed 1 Oct 2018.

26. Hostalek U, Ametov A, Barykina I, Bondar I, Vaysberg A, Verbovaya $\mathrm{N}$, et al. Multicentre evaluation of adherence to extendedrelease metformin in daily practice in Russia. Int J Diabetes Clin Res. 2017;4(2). https://clinmedjournals.org/articles/ijdcr/inter national-journal-of-diabetes-and-clinical-research-ijdcr-4-078. php?jid=ijdcr. Accessed 1 Oct 2018.

27. Donnelly LA, Morris AD, Pearson ER. Adherence in patients transferred from immediate release metformin to a sustained release formulation: a population-based study. Diabetes Obes Metab. 2009;11(4):338-42. https://doi.org/10.111 $1 / \mathrm{j} .1463-1326.2008 .00973 . x$.

28. American Diabetes Association. Standards of medical care in diabetes-2014. Diabetes Care. 2014;37:S14-80.

29. Force Clinical Guidelines Task. Global guidelines for type 2 diabetes. Diabetes Res Clin Pract. 2014;104(1):1-52.

30. Stratton IM, Adler AL, Matthews DR, Manley SE, Cull CA, Hadden D, et al. Association of glycaemia with macrovascular and microvascular complications of type 2 diabetes (UKPDS 35): prospective observational study. BMJ. 2000;321(7258):405-12.

31. GIPdatabank. Aantal gebruikers 2012-2016 voor ATC-subgroep A10BA02 : Metformine. 2018.

32. Glucophage SR. $500 \mathrm{mg}, 750 \mathrm{mg}$ and $1000 \mathrm{mg}$ prolonged release tablets - summary of product characteristics (SmPC)-(eMC) [Internet]. https://www.medicines.org.uk/emc/product/6298/smpc. Accessed 2 Oct 2018.

33. Timmins P, Donahue S, Meeker J, Marathe P. Steady-state pharmacokinetics of a novel extended-release metformin formulation. Clin Pharmacokinet. 2005;44(7):721-9. https://doi. org/10.2165/00003088-200544070-00004.

34. NIVEL. NIVEL Zorgregistraties eerste lijn-Peilstations. Incidenties en prevalenties. 2016. https://www.nivel.nl/nl/nivel-zorgregist raties-eerste-lijn/incidenties-en-prevalenties.

35. Medstone [Internet]. http://www.medstone.nl.

36. Cullen E, Liao J, Lukacsko P, Niecestro R, Friedhoff L. Pharmacokinetics and dose proportionality of extended-release metformin following administration of 1000, 1500, 2000 and $2500 \mathrm{mg}$ in healthy volunteers. Biopharm Drug Dispos. 2004;25(6):261-3. https://doi.org/10.1002/bdd.407.

37. Medicijnkosten.nl. The National Health Care Institute (ZIN) [Internet]. https://www.medicijnkosten.nl/. Accessed 15 May 2018.

38. The National Health Care Institute (ZIN). Farmacotherapeutisch Kompas [Internet]. www.farmacotherapeutischkompas.nl. Accessed 12 Nov 2018.

39. GIPdatabank. Totale kosten 2012-2016, hulpmiddelencategorie F : Diabeteshulpmiddelen. 2018.

40. Nederlandse Zorgautoriteit. OpenDIS. 2018.

41. CBS. CBS StatLine - Jaarmutatie consumentenprijsindex [Internet].. http://statline.cbs.nl. Accessed 17 Oct 2017.

42. Roze S, Duteil E, Smith-Palmer J, de Portu S, Valentine W, de Brouwer BFE, et al. Cost-effectiveness of continuous subcutaneous insulin infusion in people with type 2 diabetes in The Netherlands. J Med Econ. 2016;19(8):742-9.

43. GIPdatabank. Het aantal uitgiftes per gebruiker van diabetesmiddelen, 2002-2016.

44. Garber AJ, Duncan TG, Goodman AM, Mills DJ, Rohlf JL. Efficacy of metformin in type II diabetes: results of a doubleblind, placebo-controlled, dose-response trial. Am J Med. 1997;103(6):491-7. http://www.ncbi.nlm.nih.gov/pubmed/94288 32. Accessed 1 Oct 2018.

45. Boussageon R, Pouchain D, Renard V. Prevention of complications in type 2 diabetes: is drug glucose control evidence based? Br J Gen Pract. 2017;67(655):85-7.

46. Lawrence DB, Ragucci KR, Long LB, Parris BS, Helfer LA. Relationship of oral antihyperglycemic (sulfonylurea or metformin) 
medication adherence and hemoglobin A1c goal attainment for HMO patients enrolled in a diabetes disease management program. J Manag Care Pharm. 2006;12(6):466-71.

47. Guisasola FÁ, Mavros P, Nocea G, Alemao E, Alexander CM, Yin D. Glycaemic control among patients with type 2 diabetes mellitus in seven European countries: findings from the real-life effectiveness and care patterns of diabetes management (RECAPDM) study. Diabetes Obes Metab. 2008;10(Suppl 1):8-15.

\section{Affiliations}

\section{Judith J. Gout-Zwart ${ }^{1,2}$ (1) $\cdot$ Lisa A. de Jong ${ }^{3}$. Lisanne Saptenno ${ }^{3}$ Maarten J. Postma ${ }^{3,4,5}$}

1 Asc Academics, Westerhaven 13, 9718 AW Groningen, The Netherlands

2 Department of Nephrology, University Medical Center Groningen (UMCG), University of Groningen, Hanzeplein 1, 9713 GZ Groningen, The Netherlands

3 Unit of PharmacoTherapy, -Epidemiology and -Economics, Groningen Research Institute of Pharmacy, University of Groningen, Antonius Deusinglaan 1, 9713 AV Groningen, The Netherlands
4 Department of Economics, Econometrics and Finance, University of Groningen, Groningen, The Netherlands

5 Department of Health Sciences, University Medical Center Groningen (UMCG), University of Groningen, Hanzeplein 1, 9713 GZ Groningen, The Netherlands 